$\xi$

\title{
Technology Influence: Assistive Video or Assistive Courseware for Hearing-Impaired Learners
}

\author{
Ariffin Abdul Mutalib ${ }^{1}$, Sobihatun Nur Abdul Salam ${ }^{1}$, Mazida Ahmad $^{2}$, Massudi Mahmuddin² \\ and Sharifah Nadiya Syed Yahaya ${ }^{3}$ \\ ${ }^{1}$ School of Multimedia Technology and Communication, Universiti Utara Malaysia, 06010 Sintok, Kedah, Malaysia \\ ${ }^{2}$ School of Computing, Universiti Utara Malaysia, 06010 Sintok, Kedah, Malaysia \\ ${ }^{3}$ Politeknik Tuanku Syed Sirajuddin, Perlis, Malaysia \\ Corresponding Author Email: am.ariffin@uum.edu.my
}

\begin{abstract}
Technology has widely absorbed into daily life. In fact, various technologies have been carried out in supporting teaching and learning. In conjunction to that, this paper explains about a comparison between two technologies for hearing-impaired learners in their learning purpose. The technologies are assistive video for hearing-impaired learners (AV4HI) and assistive courseware for hearing-impaired learners (AC4HI). The rationale is that previous statement was made after learners experience normal courseware, not the courseware specifically designed for them. Hence, perhaps if the courseware is designed special for them, the hearing-impaired learners would experience differently, and behave more positive upon the AC4HI. Hence, this paper aims at describing the execution of the comparison. It involves a 3-stage process: designing the AC4HI, developing the AC4HI, and user experience. In the end, it was found that users are happy with both, but in terms of content acquisition, they prefer to have notes in the learning material.
\end{abstract}

Keywords: Assistive Technology (AT), assistive courseware, multimedia technology.

\section{Introduction}

This study believes that if the hearing-impaired students are tackled through ways they prefer to work with, their limitations in the teaching and learning context could be handled nicely. Part of the initiatives includes determining guidelines for applications for the hearing-impaired people [1]. The guidelines have been adapted and incorporated into applications for the hearing-impaired people as reported in [2] and [3]. Later, the guidelines were further refined for hearing-impaired students of higher learning institutions, which shows no big difference [4]. One of the initiatives carried out in this study is designing an appropriate learning material for them. For that reason, this study was commenced, by determining whether hearing-impaired students prefer to learn either with courseware or video. It has to be determined because the nature of courseware and video are different. Conceptually, courseware could be designed with high-level complexity,

While video just involves low level [5]. In terms of interaction style, users have to click buttons in courseware to operate and get to the content.

This is not required in video, in which the users could watch the contents that move on their own. When necessary, they could use the minimal interaction mechanism to jump to certain content [6]. Having experimented that, this study found that the hearing-impaired people prefer video more than courseware, as reported by [7]. It was done with helps of the works reported in [4].

Based on visual theories, the assistive video for hearing-impaired (AV4HI) has been designed. The concept of AV4HI has been explained in [7]. Basically, the concept is simple. This enables the teachers who teach the hearing-impaired students to design and develop their own AV4HI in support of their teaching approach. Based on the concept, a prototype has been developed. Figure 1 depicts the shots of the prototype 


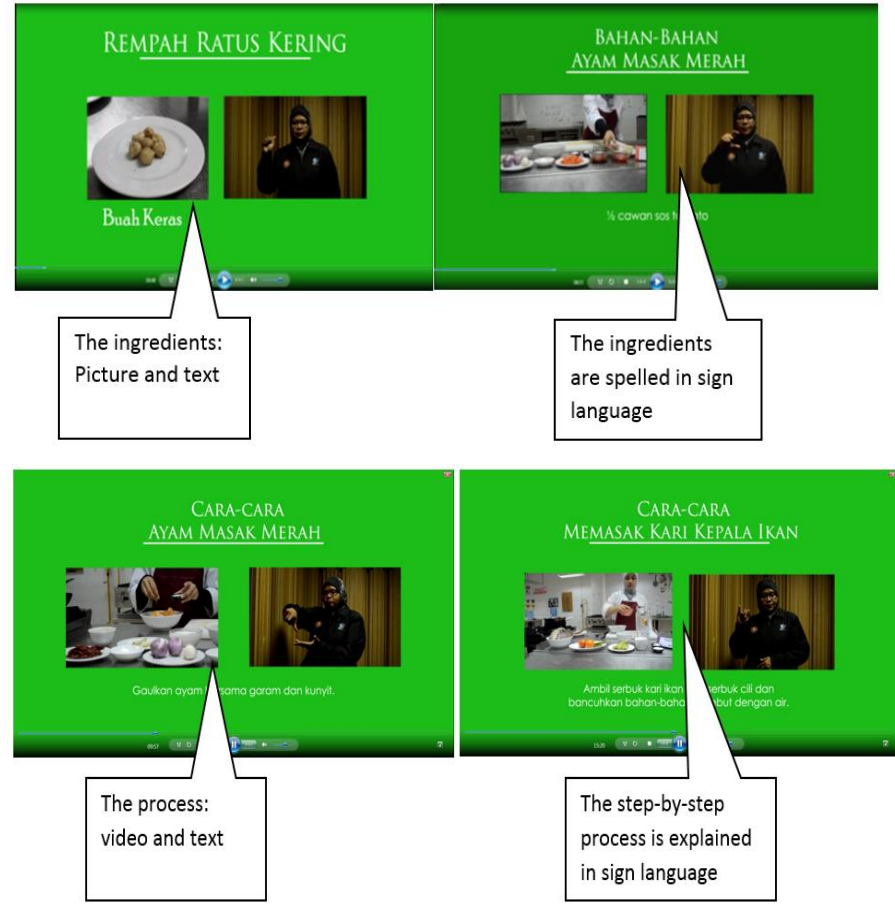

Figure 1: Snapshots of the AV4HI

Figure 1 illustrates that the AV4HI combines various content channels. The text is minimized in conveying the contents. Rather, video is used, consisting of a video displaying the process coupled with a video of sign language explaining the process being showcased.

Later, having dealt with the hearing-impaired learners and the AV4HI, this study doubts whether they really do not prefer courseware or if the courseware is designed special for meeting their needs, they may consider otherwise. Such doubt is significant because while asking on their preference in the work by [7], the hearing-impaired learners may have referred to the normal courseware they have experienced.

Accordingly, this paper enhances the existing work by comparing their experience between $\mathrm{AC} 4 \mathrm{HI}$ and assistive courseware for hearing-impaired learners (AC4HI). Consequently, this paper aims at describing the comparison and the results. This requires this study to develop the AC4HI. It is important that the AC4HI incorporates the similar concept with the AV4HI. With that, this study makes use of the existing contents in the AV4HI and composed them into AC4HI.

While this section establishes the background of the paper, the next section explains about the procedure. It is followed with a section that outlines the results. Finally, a discussion on the results follows in the next section, and ended-up with a concluding remark in the final section.

\section{Methodology}

While evidencing the results of the comparison, this study have gone through a series of systematic steps, as illustrated in Figure 2.

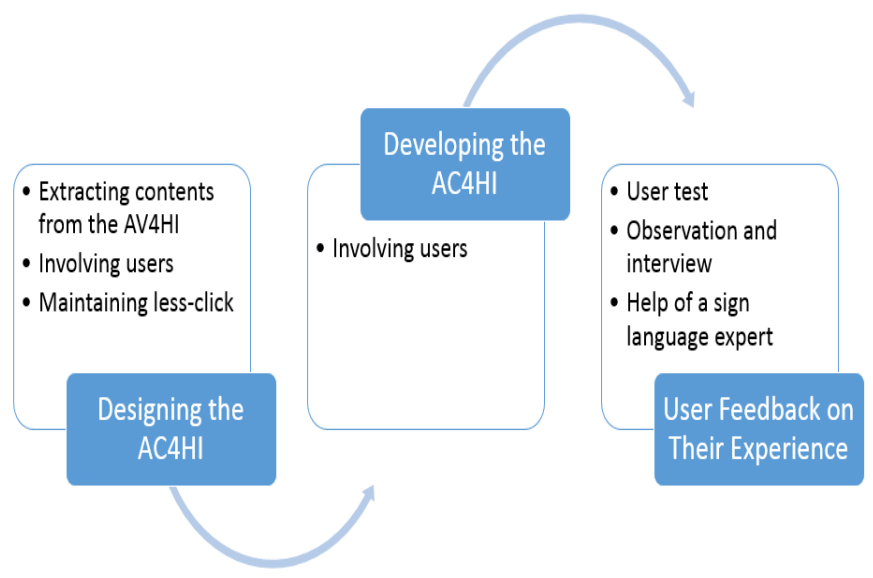

Figure 2: The procedure

In Figure 2, it is seen that the study has gone through a 3-stage process. It begins with designing the AC4HI, developing the AC4HI, and testing the AC4HI. Particularly, the designing stage was tough. It involved the real users closely. It was highly necessary to ensure the click-less element, which is very powerful in the AV4HI. This study has no worry about the contents because they were extracted from the AV4HI. Having the design agreed by the real users, it was developed in the second stage. It was not a big deal because it requires only composition works because the contents from the making of the AV4HI were re-utilized. This process also involved the users. Altogether, 12 learners who were taking hotel and catering course at Politeknik Tuanku Syed Sirajuddin were directly involved, as well as their teachers. Although only one politeknik involves, it is representable, because all hearing-impaired learners in politeknik are homogenous in terms of what and how they learn. They involve in all stage of development until the final user test. Further, the finished AC4HI (described in fig. 3 through fig. 6) was distributed to the real users to experience. They were observed while playing around with the AC4HI. Then, they were interviewed, with helps of a sign language interpreter. This study selects the observation and interview techniques for colecting data because they are the most convenient for gathering reliable data from the subject, a small group of hearingimpaired. Through the techniques, rich data could be obtained for a deep understanding. Survey and other techniques are not appropriate for this small group because the space to prompt is too narrow, which this study takes it as a drawback. Moreover, this study has been working with the subjects very closely, hence the observation and interviews are free of biasness.

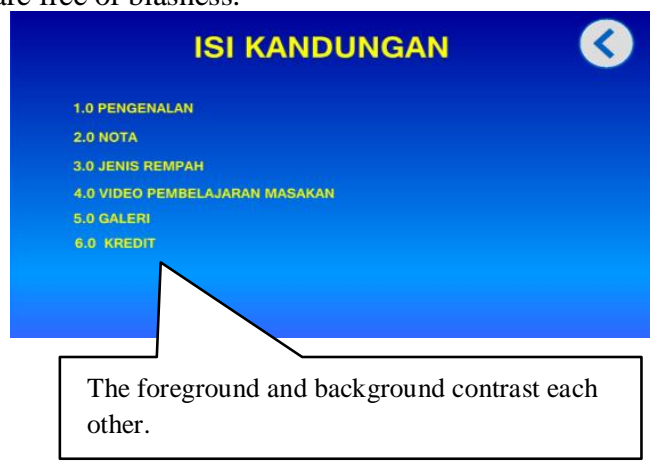




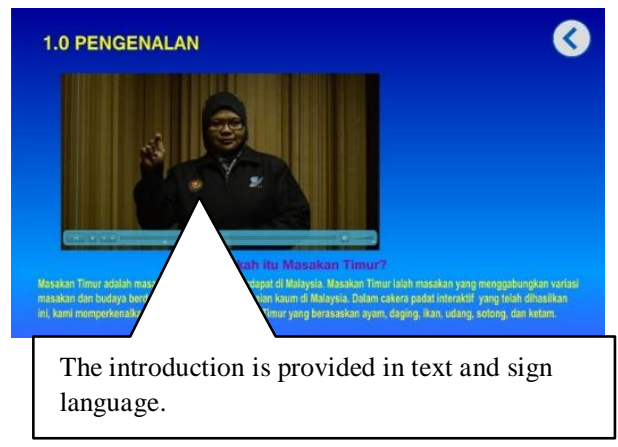

Figure 3: Main menu and the introduction to the contents in the AC4HI

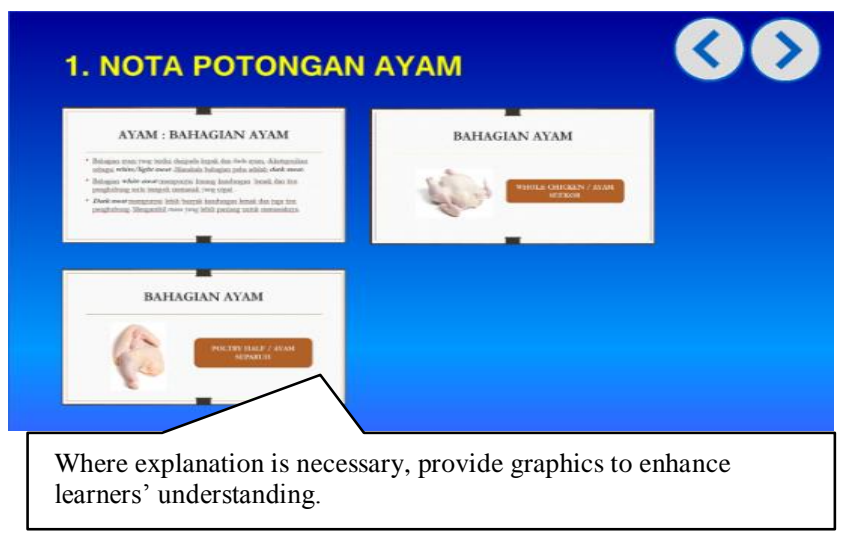

(4)

\subsection{VIDEO PEMBELAJARAN MASAKAN}

2. NOTA POTONGAN IKAN

3. NOTA SANITASI

KESELURUHAN CARA-CARA MEMASA

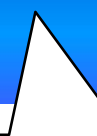

Hearing-impaired learners should not be overloaded with too many options on screen. Where possible, add page.
AYAM MASAK MERAH

KETAM MASAK CILI

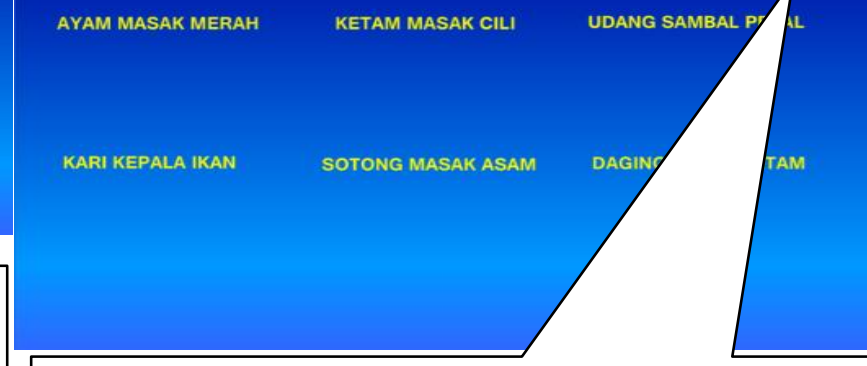

Provide clear and easy navigation style for hearing-impaired learners.

Figure 4: The way text helps

Figure 5: The explanation and navigation

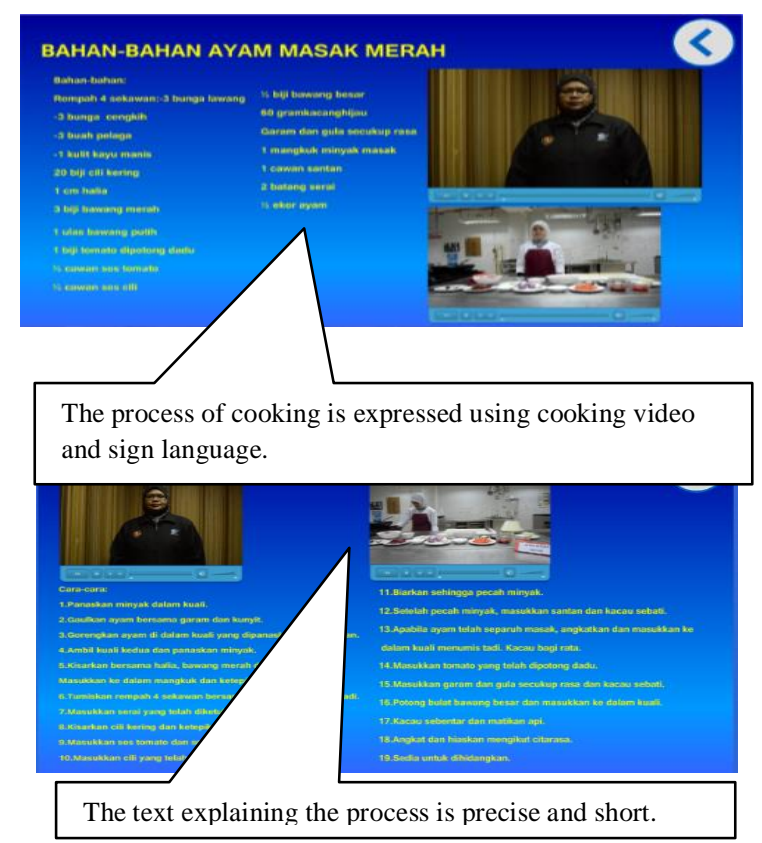

Figure 6: Explanation for process 


\section{Findings and Discussion}

The learners (altogether 12) were experiencing the AC4HI in their natural setting in Politeknik Tuanku Syed Sirajuddin (the test-bed). It was aranged by their lecturers. Although the AV4HI was also prepared, it was not involved in the testing because they have been using the material in their study. During the testing, this study observed their behavior. After the session, this study then interviewed them to understand further. While the contents and other aspects are inherited from the AV4HI, this study focused the observation on two aspects only, i.e. navigation and content acquisition. This is because they are two aspects being redesigned in the AC4HI. Through the observation, the hearing-impaired learners were noticed enjoying the AC4HI. While the findings are too rich, Table 1 summarizes them.

Table 1 Findings from observation

\begin{tabular}{|l|l|}
\hline \multicolumn{1}{|c|}{ Table 1 Findings from observation } \\
\hline \multirow{5}{*}{ Navigation } & $\begin{array}{l}\text { The learners were able to quickly learn the } \\
\text { navigation style. Having learned, they were able to } \\
\text { memorize. This ensures the navigation does not } \\
\text { delay their interaction with the AC4HI. With the } \\
\text { navigation style, they are able to control their flow. } \\
\text { They were seen clicking the menu and watch the } \\
\text { contents, and change the contents freely. Most of } \\
\text { the times, the learners were seen chatting with their } \\
\text { peers (in sign language), nodding, and smiling. }\end{array}$ \\
\hline \multirow{5}{*}{ Content acquisition } & $\begin{array}{l}\text { The learners were seen able to grab the contents } \\
\text { easily. Their facial expressions showed no negative } \\
\text { sign upon the content acquisition. Through their } \\
\text { thump-ups, nodding, and peer-chat, this study is } \\
\text { confident that they have no problem to access the } \\
\text { content. }\end{array}$ \\
\hline
\end{tabular}

As a consequence from the observation, the learners were interviewed. Details of the interview are outlined in Table 2.

Table 2 Findings from interview

\begin{tabular}{|c|c|}
\hline Aspect & Strength \\
\hline $\begin{array}{c}\text { Do you feel any } \\
\text { difference between } \\
\text { AC4HI and AV4HI? }\end{array}$ & $\begin{array}{l}\text { They are similar in terms of contents. The } \\
\text { difference is in the way we view the contents. In } \\
\text { AV4HI, we only watch. We go through with flow, } \\
\text { if we want to go certain location, such as from } \\
\text { "ayam masak merah" to another menu, we have to } \\
\text { guess. That is quite an excise. In contrast, in } \\
\text { AC4HI, we are sure where to click. Then, once we } \\
\text { click, we watch the content just like in AV4HI. } \\
\text { On the other hand, the navigation in AC4HI is } \\
\text { minimal. We believe that the contents in AC4HI are } \\
\text { taken from that in the AV4HI, and being redesigned } \\
\text { to inject the control mechanism. So, we believe that } \\
\text { with the minimal control mechanism, we could } \\
\text { make our learning more efficient. Particularly, we } \\
\text { could jump to our desired content more confidently. }\end{array}$ \\
\hline $\begin{array}{l}\text { Could you access the } \\
\text { contents efficiently? }\end{array}$ & $\begin{array}{l}\text { In AV4HI, we just watch like watching TV. Of } \\
\text { course we can pause if we want to, and slide the } \\
\text { controller to our desired location if necessary. That } \\
\text { is the only control we have. The explanation on the } \\
\text { cooking steps are in video only, without text. Also, } \\
\text { there is no note in AV4HI for us to read and get } \\
\text { information from. It is necessary for us, because } \\
\text { sometimes we prefer not to watch video, but to read } \\
\text { from text. There should be options for us. } \\
\text { In contrast, in AC4HI, there are text provided for us, } \\
\text { with images and graphics. With that, we could } \\
\text { select either watching video contents or read text. } \\
\text { In AV4HI, where there are sign language and action, } \\
\text { they are side-by-side. But in AC4HI, there are some } \\
\text { parts they are top-bottom. For us, the top-bottom }\end{array}$ \\
\hline
\end{tabular}

\begin{tabular}{|c|l|}
\hline & $\begin{array}{l}\text { layout is quite inefficient. We rely strongly on our } \\
\text { sight, so moving eyes top and bottom is an excise, } \\
\text { not like left-right. }\end{array}$ \\
\hline \multirow{2}{*}{$\begin{array}{l}\text { Well, actually, both AV and AC are good. We } \\
\text { appreciate them very much. Of course sometimes } \\
\text { we prefer to watch only, then we go for AV. When } \\
\text { we have something that requires us to get certain } \\
\text { contents dynamically, we could go for AC. So, } \\
\text { there is no specific answer if we have to choose } \\
\text { between AC and AV. } \\
\text { In terms of contents, we prefer the AC of course, } \\
\text { because it contains textual notes. However, if the } \\
\text { courseware is designed not specific for us, we will } \\
\text { face too much difficulties. }\end{array}$} \\
\hline
\end{tabular}

Based on the findings from the observation and interview, it could be understood that the users are happy to use the AC4HI. At the same time, they never mention that the AV4HI is not preferred. However, it is notified through the comparison that textual contents are also preferred. Regarding that, it has to be realized that the textual contents in the AC4HI are designed specific for them, meeting their requirement.

This study agrees also with them because in learning, written contents are more tangible for the learners, and the ability to absorb them through seeing is more powerful. Hence, future studies have to

consider this in the design of contents for hearing-impaired. Although the AC4HI requires the learners to put some efforts, the real contents are still in their preferred posture [8]. Besides that, the approach in the AC4HI itself, which combines various media elements including text, video, and sign language makes them able to understand the contents well. This reduces their cognitive load [9]. This agrees with the findings in the previous studies such as [10 12].

\section{Conclusion}

This study has proven that if a courseware is designed specifically for the needs of hearing-impaired learners, they are open to utilize it, as outlined by famous experts such as in [12 - 16]. Regarding that, the design of $\mathrm{AC}$ is of course different than that for normal learners because their limitations are different. Based on the responses of the interview, although the learners have not addressed whether they prefer AC or AV more than the other, this study understands that they both could be utilized. However, when it is discovered that the note element is necessary, than, if designers want to come out with an AV, they need to find ways to provide the notes. Regarding that, it could be easily designed in AC. This is expected that the hearing-impaired learners could get the benefits of technologies when more designers realize about their necessities.

This paper reports on a comparison between a courseware and a video. At the same time, it is generally known and proven that animation is also impactful in presenting information. While its potentials for the hearing-impaired education has not been discovered, this study intends to carry out another study in future to prove an evidence.

\section{Acknowledgement}

This study has been funded by Universiti Utara Malaysia (UUM) under High Impact Group Research project. Accordingly, it is a great honor to express our gratitude to UUM. Most of works were carried out involving Politeknik Tuanku Syed Sirajuddin (PTSS) as the testbed. Hence, a big thank you goes to PTSS also. 


\section{References}

[1] A. M. Ariffin \& M. Faizah. (2010). Guidelines of Assistive Courseware (AC) for Hearing Impaired Students. In Proceedings of Knowledge Management International Conference 2010. UUM.

[2] A. Nurulnadwan, S. Zatul Amilah, M.R. Nur Hazwani, A.A. Nurul Ulfa, A.M. Ariffin \& J. Mohd Saifullizam. (2011). Assistive Courseware for Hearing Impaired Learners in Malaysia. In Proceedings of International Conference on Advanced Science, Engineering and Information Technology 2011.

[3] S. Zatul Amilah, A. Nurulnadwan, A.M. Ariffin, \& J. Mohd Saifullizam. (2011). Assistive Courseware for Hearing-impaired Learners in Malaysia based on Theory of Multiple Intelligence (MI). International Journal of Computer Sciences and Emerging Technologies. 2(6). 370-377.

[4] A.M. Ariffin, S.Y. Syarifah Nadiya, A.S. Sobihatun Nur, (2012). Learning Object for the Hearing-Impaired: design and development of Koswer Pendidikan Islam Tunakerna (KOSPIT). In Proceedings of International Conference on Knowledge Management International Conference (KMICe 2012).251-155.

[5] T.K. Borsook \& N. Higginbotham-Wheat, (1991). Interactivity: What is it and what can it do for computer-based instruction. Educational Technology. 31(10). 11-17.

[6] A. Dix, J. Finlay, G.D. Abowd \& R. Beale, (2004). Human-computer Interaction 3rd edition. Pearson Education Limited. England.

[7] A.M. Ariffin, S.Y. Syarifah Nadia, A.S. Sobihatun Nur, A. Mazida, \& M. Massudi. (2014). Assistive Contents for Hearing-Impaired People. In Proceedings of Knowledge Management International Conference 2014, pp. 885-888.

[8] C. Karat, C. Pinhanez, J. Karat, R. Arora, \& J. Vergo, (2001). Less clicking, more watching: Results of the iterative design and evaluation of entertaining web experiences. In Proceedings of Interact'2001, Tokyo, Japan.

[9] J. Sweller, (1988), Cognitive load during problem solving: Effects on learning, Cognitive Science, 12, 257-285.

[10] N. Adamo-Villani \& K. Wright, (2007). SMILE: an immersive learning game for deaf and hearing children. ACM Proceedings of SIGGRAPH 2007- Educators, 5-10 August 2007, San Diego, ACM Digital Library. New York: ACM Publications.

[11] M.A. El-Soud, A.E. Hassan, M.S. Kandil, \& S.M. Shohieb, (2010), A proposed web based framework e-learning and dictionary system for deaf Arab students. International Journal of Electrical \& Computer Sciences. 10(1).

[12] J. Preece, Y. Rogers, \& H. Sharp, (2007). Interaction Design: beyond human-computer interaction 2nd edition. John Wiley\& Sons, Ltd. England.

[13] D.J. Mayhew, (1999). The Usability Engineering Lifecycle. Morgan Kaufmann, San Francisco

[14] B. Schneiderman, (1998). Designing the user interface. Strategies for effective human-computer interaction. 3rd ed. Addison-Wesley: Reading, MA

[15] J. Nielsen, T. Clemmensen, \& C. Yssing, (2002). Getting access to what goes on in people's head?: Reflections on the think-aloud technique. In Proceedings of the second Nordic conference on humancomputer interaction. ACM Press. 101-110.

[16] J.G. Jesse, (2000). The elements of user experience. User-centered design for the web. USA: New Riders. 